\title{
COPD patients' self-reported adherence, psychosocial factors and mild cognitive impairment in pulmonary rehabilitation
}

This article was published in the following Dove Press journal: International Journal of COPD

18 July 2017

Number of times this article has been viewed

\author{
Antonia Pierobon' \\ Elisa Sini Bottelli' \\ Laura Ranzini' \\ Claudio Bruschi \\ Roberto Maestri ${ }^{3}$ \\ Giorgio Bertolotti ${ }^{4}$ \\ Marinella Sommaruga ${ }^{5}$ \\ Valeria Torlaschi' \\ Simona Callegari' \\ Anna Giardini' \\ 'Psychology Unit, ${ }^{2}$ Department \\ of Pulmonary Rehabilitation, \\ ${ }^{3}$ Department of Biomedical \\ Engineering, Istituti Clinici Scientifici \\ Maugeri, IRCCS, Montescano, \\ ${ }^{4}$ Psychology Unit, Istituti Clinici \\ Scientifici Maugeri, IRCCS, Tratate, \\ ${ }^{5}$ Clinical Psychology and Social \\ Support Unit, Istituti Clinici Scientifici \\ Maugeri, IRCCS, Camaldoli, Italy
}

Correspondence: Antonia Pierobon Servizio di Psicologia, Istituti Clinici Scientifici Maugeri SpA-SB, IRCCS, Istituto di Montescano, 27040

Montescano, PV, Italy

Tel +39385 247255

Fax +39 $3856 \quad 1386$

Email antonia.pierobon@icsmaugeri.it
Abstract: In addition to clinical comorbidities, psychological and neuropsychological problems are frequent in COPD and may affect pulmonary rehabilitation delivery and outcome. The aims of the study were to describe a COPD population in a rehabilitative setting as regards the patients depressive symptoms, anxiety, mild cognitive impairment (MCI) and self-reported adherence and to analyze their relationships; to compare the COPD sample MCI scores with normative data; and to investigate which factors might predict adherence to prescribed physical exercise. This was a multicenter observational cross-sectional study. Of the 117 eligible stable COPD inpatients, 84 were enrolled according to Global initiative for chronic Obstructive Lung Disease (GOLD) criteria (mainly in Stage III-IV). The assessment included Mini Mental State Examination (MMSE), Montreal Cognitive Assessment (MoCA), anxiety, depression and self-reported pharmacological and nonpharmacological adherence. From the MMSE, 3.6\% of patients were found to be impaired, whereas from the MoCA 9.5\% had a likely MCI. Patients referred had mild-severe depression (46.7\%), anxiety $(40.5 \%)$, good pharmacological adherence $(80.3 \%)$ and difficulties in following prescribed diet (24.1\%) and exercise (51.8\%); they struggled with disease acceptance (30.9\%) and disease limitations acceptance (28.6\%). Most of them received good family (89\%) or social (53\%) support. Nonpharmacological adherence, depression, anxiety and MCI showed significant relations with 6-minute walking test, body mass index (BMI) and GOLD. Depression was related to autonomous long-term oxygen therapy modifications, disease perception, family support and MCI. In the multivariate logistic regression analysis, higher BMI, higher depression and lower anxiety predicted lower adherence to exercise prescriptions $(P=0.0004$, odds ratio $=0.796,95 \% \mathrm{CI}=0.701,0.903 ; P=0.009$, odds ratio $=0.356$, $95 \% \mathrm{CI}=0.165,0.770$; and $P=0.05$, odds ratio $=2.361,95 \% \mathrm{CI}=0.995,5.627$ respectively). In COPD patients, focusing on pharmacological and nonpharmacological adherence enhance the possibility of tailored pulmonary rehabilitation programs.

Keywords: depression, anxiety, mild cognitive impairment, adherence, COPD, pulmonary rehabilitation

\section{Introduction}

Pulmonary rehabilitation is a suitable treatment for COPD since it reduces symptoms, decreases disability, increases participation in physical and social activities and improves the overall health-related quality of life (HRQoL) in patients with chronic respiratory disease. ${ }^{1-3}$ Nevertheless, pulmonary rehabilitation is not often prescribed and patients often do not follow the prescribed exercise training in everyday life. ${ }^{4,5}$ In addition to the well-known clinical comorbidities, cognitive impairment, anxiety, depression, and low adherence to clinical prescriptions are frequent and may affect pulmonary rehabilitation 
delivery. ${ }^{3,6-8}$ Moreover, self-efficacy on exercise could play an important role in patients' pulmonary rehabilitation attendance and in improving functional outcomes. ${ }^{9}$

Attention and executive dysfunctions are frequent features of mild cognitive impairment (MCI) in COPD. ${ }^{10,11}$ Furthermore, patients with COPD report high levels of anxiety and depression, which are associated with disease severity and are related to psychosocial constructs, such as poor quality of life, living alone, female sex, smoking and low socioeconomic status. ${ }^{12-14}$ Anxiety and depression identified in subjects with stable COPD were significantly associated with increased overall length of event-based exacerbations in patients with at least one exacerbation. ${ }^{15}$ Moreover, depression is a risk factor for increased COPD exacerbations, hospitalizations and mortality. ${ }^{16}$

In COPD management, good pharmacological adherence decreases the frequency and severity of exacerbations, improves overall HRQoL and prolongs survival. ${ }^{17}$ Unfortunately, half of COPD patients abandon the treatment with inhaled medication during the first year of therapy. ${ }^{18}$ Furthermore, even if prescribed, less than half of the patients use oxygen therapy and only $25 \%$ of patients use oxygen therapy during activities outside their house. ${ }^{19}$

Accurate measurement of medication adherence is important in terms of both research and clinical practice. There are many methods to assess adherence; direct (objective physiological/biochemical analysis) or indirect ones (objective monitoring of medication usage or patient's self-report). Each method has advantages and disadvantages, but no single method is sufficiently reliable and accurate; thus, a combination of assessment methods may be preferred in order to increase validity and reliability of the information collected. ${ }^{20}$ Moreover, as described in the literature, most of the tools used to assess adherence and the interventions to enhance medication adherence do not focus on behavioral prescriptions, but focus mainly on taking or not taking drugs. ${ }^{7}$

To the best of our knowledge, there is a lack of scientific literature describing simultaneously the associations between depressive symptoms, anxiety, MCI and self-reported adherence in COPD patients.

The aims of this study are: 1) to describe a COPD population in a rehabilitative setting as regards their depressive symptoms, anxiety, MCI and self-reported pharmacological and nonpharmacological adherence; 2) to compare the COPD sample MCI scores with normative data; 3) to analyze the relationships between self-reported adherence to behavioral prescriptions and clinical, psychological, neuropsychological variables; and 4) to investigate which factors might predict adherence to exercise at home following medical advice.

\section{Methods}

\section{Subjects}

For this multicenter observational cross-sectional study, all patients with COPD consecutively admitted to the Clinical Scientific Institutes Maugeri, IRCCS - Department of Pulmonary Rehabilitation, Montescano (PV), Camaldoli (MI) and Tradate (VA) - from September 2013 to March 2014 were considered eligible. Patients were diagnosed according to Global initiative for chronic Obstructive Lung Disease (GOLD) criteria (Stage II-IV, C-D); they were in clinically stable condition (no exacerbations in the last 3 months) with optimized stable pharmacological therapy (inhalation therapy with long-acting anticholinergic and/or $\beta 2$-agonists, inhaled corticosteroids when needed).

The exclusion criteria were severe medical conditions that did not allow assessment (severe chronic inflammatory diseases, chronic heart failure, neoplastic diseases, acute respiratory diseases), no Italian education or relapse into illiteracy, severe visual-perceptive deficits, low subjective motivation or refusal to undergo the evaluation, severe psychiatric disorders (by medical psychiatric evaluation) and severe cognitive deterioration (Mini Mental State Examination [MMSE] score $\leq 18.3){ }^{21}$

All the patients signed written informed consent form for this study. The study was approved by our institutional Review Board and Central Ethical Committee belonging to the ICS Maugeri SpA SB (CEC) (approval number: CEC N.927, 27/06/2013).

\section{Procedure}

All patients were admitted to an inpatient comprehensive rehabilitation program: educational sessions, exercise training (cycloergometer and/or treadmill, arms ergometer), respiration against resistance, calisthenics, psychological counseling, and metabolic evaluation with a personalized diet when needed.

During the first week of admission, all enrolled patients underwent an individual psychological and neuropsychological assessment.

The psychological and neuropsychological assessment included the Hospital Anxiety and Depression Scale (HADS), ${ }^{22}$ the 30-point Geriatric Depression Scale (GDS), ${ }^{23}$ the Beck Depression Inventory (BDI-II), ${ }^{24}$ the Morisky, Green, and Levine Adherence Scale (MGL Adherence Scale), ${ }^{25}$ the Adherence Schedule in Chronic Obstructive Lung Disease - Revised (ASiCOLD-R), ${ }^{26}$ the $\mathrm{MMSE}^{21}$ and the Montreal Cognitive Assessment (MoCA). ${ }^{27}$

The psychological and neuropsychological assessment was divided in two sessions: 1) MMSE and psychological 
test, and 2) MoCA, which was administered a few days later in order to avoid an interference effect.

Trained psychologists evaluated the patients according to standardized administration and scoring procedures. The patients were supported throughout the testing period to maintain motivation and to elicit the optimal level of performance; a break was always allowed if necessary.

\section{Instruments}

MMSE was adopted to screen for cognitive impairment according to the Measso et al distribution; at a $0.95 \leq \alpha \leq 0.99$ confidence level, the score range of 18.3-23.8 could be associated with moderate, and no severe, cognitive impairment, with a high probability that those scores reflected a diminished performance for reasons other than aging or poor education. ${ }^{21}$

The MoCA was used as a screening instrument for MCI by assessing memory, language, executive functions, visuospatial skills, calculation, abstraction, attention, concentration and orientation. The MoCA is freely accessible for clinical and educational purposes; it is available in 36 languages, including Italian (www.mocatest.org). Recent normative data can be used to assess MCI with the equivalent scores (ES) classification, with more precision than the standard cutoff ( $\leq 26) ; 9,27$ for normative data we referred to the Conti et al classification, in line with the distribution of our patient sample. ${ }^{28}$ In this study, MoCA scores were categorized as Yes MCI (ES 0) and No MCI (ES 1-4) according to the ES, where 0 corresponds to an inferentially controlled judgment of being below the norm; 4 is equal to or better than the 50th percentile; and 1,2 and 3 are obtained by dividing into three equal parts the area of the distribution between 0 and 4 are considered as not impaired (37). Therefore, Yes MCI identified patients with an MCI stemming from MoCA data. ${ }^{28}$

The level of anxiety was evaluated by HADS-A, ${ }^{29}$ specific for hospitalized patients. HADS-D (depressive symtoms) was not considered. BDI-II for younger patients ( $<65$ years) and GDS for older patients ( $\geq 65$ years) were adopted due to their excellent reliability compared to HADS-D and due to items' content and number. ${ }^{30}$ The BDI-II patients' scores were corrected according to sex and divided into percentile points. Depressive and anxious symptoms scores were also classified into low (none or mild) and moderate/severe (moderate or severe).

Self-reported adherence to medical plans was assessed by MGL Adherence Scale and ASiCOLD-R. The well-known MGL Adherence Scale was adopted for evaluating pharmacological adherence and the total score was considered (range 0-4). ${ }^{25}$ The ASiCOLD-R (Appendix A) belongs to a wider group of schedules aimed at assessing the cognitive, relational and behavioral antecedents of self-reported adherence to treatment in different chronic diseases (chronic heart failure, cardiovascular heart disease, asthma, COPD). The ASiCOLD-R investigates a patient's disease perception such as disease acceptance (DA), disease limitations acceptance (DLA), family/social support and self-efficacy in disease management in relation to pharmacological and nonpharmacological prescriptions (eating, smoking, exercise, long-term oxygen therapy [LTOT]) (see Appendix A). ASiCOLD-R answers were classified into low (not at all, a little) and moderate/high (enough/much/very much) disease perception and self-efficacy in following medical prescriptions. ${ }^{26}$

\section{Statistical analysis}

Descriptive statistics are reported as mean \pm SD for continuous variables and as $\mathrm{n}$ (frequency percentage) for discrete variables.

Differences between groups for continuous variables were assessed by Student's $t$-test for unpaired samples or by Mann-Whitney test when appropriate. Comparisons of categorical variables were carried out by chi-square test or Fisher's exact test when appropriate.

To identify which factors were independent predictors of adherence to exercise prescriptions (dependent variable), we developed a multivariate predictive model (logistic regression) using the following candidate predictors: age, sex, DA, DLA, depression, anxiety, MCI and body mass index (BMI). To avoid overfitting, less predictive variables were eliminated by a backward elimination procedure at the significance level of 0.1 .

All statistical tests were two-tailed, and statistical significance was set at $P<0.05$. All analyses were carried out using the SAS/STAT statistical package, release 9.2 (SAS Institute Inc., Cary, NC, USA).

\section{Results}

In our multicenter cross-sectional observational study, 117 inpatients affected by COPD, stage II-IV GOLD, were considered eligible, but 33 of them were excluded $(n=4$, clinical exacerbation during hospitalization; $n=4$, relapse into illiteracy; $n=4$, visual-perceptive deficits; $n=16$, low subjective motivation to undergo the evaluation, or refusal; $\mathrm{n}=5$, severe psychiatric diseases). Eighty-four patients were included in the study.

Tables 1 and 2 show the sociodemographic and clinical characteristics.

Table 3 illustrates the psychological and neuropsychological assessment scores (depression, anxiety, cognitive deterioration and $\mathrm{MCI}$ ). Regarding the cognitive functions, $3.6 \%$ of COPD patients were found to be impaired as 
Table I Psychosocial and clinical characteristics of the study sample $(n=84)$

\begin{tabular}{|c|c|}
\hline & n (\%) \\
\hline \multicolumn{2}{|l|}{ Sex } \\
\hline Male & $63(75.0)$ \\
\hline Female & $21(25.0)$ \\
\hline \multicolumn{2}{|l|}{ Education (school years) } \\
\hline$\leq 5$ & $30(35.7)$ \\
\hline $6-8$ & $37(44.0)$ \\
\hline $9-13$ & $16(19.1)$ \\
\hline$\geq 14$ & I (I.2) \\
\hline \multicolumn{2}{|l|}{ Lives alone } \\
\hline No & $66(78.6)$ \\
\hline Yes & $18(2 \mid .4)$ \\
\hline \multicolumn{2}{|l|}{ Marital status } \\
\hline Married/common-law partner & $46(54.8)$ \\
\hline Widower & $15(17.9)$ \\
\hline Unmarried & $12(14.3)$ \\
\hline Separated/divorced & II (I3.0) \\
\hline \multicolumn{2}{|l|}{ Current occupation } \\
\hline Retired & $79(94.1)$ \\
\hline Employed & $5(5.9)$ \\
\hline \multicolumn{2}{|l|}{ Primary caregiver } \\
\hline Nobody & $38(45.2)$ \\
\hline Husband/wife/partner & $21(25.0)$ \\
\hline Daughter/son & $19(22.6)$ \\
\hline Other family member/carer & $6(7.2)$ \\
\hline \multicolumn{2}{|l|}{ Smoker } \\
\hline No & $6(7.1)$ \\
\hline Yes & $13(15.5)$ \\
\hline Ex-smoker & $65(77.4)$ \\
\hline \multicolumn{2}{|l|}{ COPD - severity (GOLD) } \\
\hline I-Low $\left(F E V_{1} /\right.$ FVC $\left.<70 \%, \mathrm{FEV}_{1} \geq 80 \%\right)$ & 0 \\
\hline II-Moderate $\left(50 \% \leq \mathrm{FEV}_{1}<70 \%\right)$ & $28(33.3)$ \\
\hline III-Severe $\left(30 \% \leq \mathrm{FEV}_{1}<50 \%\right)$ & $31(36.9)$ \\
\hline IV-Very severe $(\mathrm{FEV},<30 \%)$ & $25(29.8)$ \\
\hline \multicolumn{2}{|l|}{ LTOT } \\
\hline No & $26(31.0)$ \\
\hline Yes & $58(69.0)$ \\
\hline
\end{tabular}

Abbreviations: GOLD, Global Initiative for Chronic Obstructive Lung Disease; $\mathrm{FEV}_{\text {, }}$, forced expiratory volume in I second; FVC, forced vital capacity; LTOT, longterm oxygen therapy.

Table 2 Clinical characteristics of the study sample $(n=84)$

\begin{tabular}{lll}
\hline & Mean & SD \\
\hline Age (years) & 70.2 & 7.0 \\
Months of illness & 105.1 & 81.5 \\
6MWT (minutes) & 334.5 & 118.5 \\
${\text { BMI }\left(\mathrm{kg} / \mathrm{m}^{2}\right)}_{\mathrm{FEV}_{1}(\mathrm{~L})}$ & 26.0 & 6.7 \\
$\mathrm{FEV}_{1} \%$ & 1.1 & 0.5 \\
FVC (L) & 44.2 & 18.6 \\
FVC\% & 2.4 & 0.8 \\
FEV $/$ FVC & 76.3 & 20.5 \\
\hline
\end{tabular}

Abbreviations: 6MWT, 6-minute walking test; BMI, body mass index; FEV expiratory volume in I second; FVC, forced vital capacity.
Table 3 Psychological and neuropsychological characteristics of the study sample $(n=84)$

\begin{tabular}{ll}
\hline & $\mathbf{n}(\%)$ \\
\hline Anxiety symptoms (HADS-A) & \\
None (0-7) & $50(59.5)$ \\
Mild (8-I0) & $20(23.8)$ \\
Moderate (II-I4) & $11(13.1)$ \\
Severe (I5-2I) & $3(3.6)$ \\
Depressive symptoms (BDI-II/GDS) & \\
None & $44(53.3)$ \\
Mild & $14(16.9)$ \\
Moderate & $13(15.5)$ \\
Severe & $12(14.3)$ \\
Cognitive deterioration (MMSE) & \\
I8.3 $\geq x \leq 23.8$ & $3(3.6)$ \\
$>23.8$ & $81(96.4)$ \\
MCl (MoCA - ES*) & \\
0 & $8(9.5)$ \\
I & $13(15.5)$ \\
2 & $17(20.2)$ \\
3 & $14(16.7)$ \\
4 & $32(38.1)$ \\
\hline
\end{tabular}

Notes: ES* correspond to a five-point interval scale divided as follows: 0 indicates a performance to the worst $5 \%$ of the population; 4 indicates scores higher than the median value of the whole sample; I, 2 and 3 are obtained by dividing into three equal parts the area of the distribution between 0 and 4 (37).

Abbreviations: HADS-A, Hospital Anxiety and Depression Scale-Anxiety; BDI-II, Beck Depression Inventory-second edition; GDS, Geriatric Depression Scale; MMSE, Mini Mental State Examination; MCl, Mild Cognitive Impairment; MoCA, Montreal Cognitive Assessment; ES, equivalent scores.

per the MMSE. From the MoCA test, COPD patients were more likely to have an $\mathrm{MCI}$ in comparison with normative cognitive data $(9.5 \%$ vs $2.6 \%, P=0.0006) .{ }^{28}$

The MGL Adherence Scale total score highlighted that only $16.7 \%$ of COPD patients reported low pharmacological adherence. Table 4 shows the ASiCOLD-R score

Table 4 ASiCOLD-R: item score frequencies and percentage $(n=84)$

\begin{tabular}{|c|c|c|}
\hline ASiCOLD-R - items & $\begin{array}{l}\text { Low } \\
\text { n (\%) }\end{array}$ & $\begin{array}{l}\text { Moderatel } \\
\text { high n (\%) }\end{array}$ \\
\hline \multicolumn{3}{|l|}{ Disease perception } \\
\hline Disease acceptance & $26(30.9)$ & $58(69.1)$ \\
\hline Disease limitations acceptance & $24(28.6)$ & $60(71.4)$ \\
\hline $\begin{array}{l}\text { Perceived family support in } \\
\text { disease management }\end{array}$ & $9(10.0)$ & $73(89.0)$ \\
\hline $\begin{array}{l}\text { Perceived social support in } \\
\text { disease management }\end{array}$ & $39(46.0)$ & $44(53.0)$ \\
\hline \multicolumn{3}{|l|}{ Self-efficacy } \\
\hline $\begin{array}{l}\text { Autonomous LTOT modifications } \\
\text { (LTOT, } n=58)\end{array}$ & 51 (87.9) & $7(12.1)$ \\
\hline Following dietary prescriptions & $20(24.1)$ & $63(75.9)$ \\
\hline Avoiding smoking (smoking, $\mathrm{n}=16$ ) & $9(56.2)$ & $7(43.3)$ \\
\hline $\begin{array}{l}\text { Exercising following medical } \\
\text { advice }\end{array}$ & $43(51.8)$ & $40(48.2)$ \\
\hline
\end{tabular}

Abbreviations: ASiCOLD-R, Adherence Schedule in Chronic Obstructive Lung Disease - Revised; LTOT, long-term oxygen therapy. 
distribution relating to disease perception and self-efficacy on nonpharmacological clinical prescriptions.

By comparing sociodemographic variables with ASiCOLD-R, depression and anxiety scores, no significant relations were found. The ASiCOLD-R items that refer to perceived social support, following dietary prescription, exercising following medical advice and avoiding smoking did not show significant associations with depression, anxiety and MCI. There was no significant relationships between ASiCOLD-R, depression, anxiety scores and MCI when compared with months of illness and spirometric parameters (forced expiratory volume in 1 second $\left[\mathrm{FEV}_{1}\right], \mathrm{FEV}_{1} \%$ predicted, forced vital capacity [FVC], $\mathrm{FVC} \%$ predicted, $\mathrm{FEV}_{1} / \mathrm{FVC}$ ).

DA was significantly related to depressive symptoms $(P=0.0015)$, anxiety $(P=0.03)$ and $\mathrm{MCI}(P=0.01)$; patients with higher DA reported lower depression and anxiety symptoms and were less likely to have cognitive impairment. DLA was proved to be significantly related to depressive symptoms $(P=0.0004)$ and anxiety $(P=0.02)$; patients with higher DLA reported lower depression and anxiety symptoms. Significantly lower depressive symptoms were reported by patients with a higher familial support and by patients referred for less frequent LTOT modifications ( $P=0.02, P=0.03$ respectively). The 6-minute walking test (6MWT) was significantly related to DLA; patients with low DLA walked shorter distances than patients with moderate/ high DLA (288.0 \pm 97.0 vs $354.0 \pm 122.0$ minutes, $P=0.031$ ). Patients with low adherence to dietary prescriptions had a higher BMI than patients with moderate/high adherence to dietary prescriptions ( $28.6 \pm 6.2$ vs $\left.25.2 \pm 6.7 \mathrm{~kg} / \mathrm{m}^{2}, P=0.05\right)$. Patients with low adherence to exercise following medical advice had a higher BMI than patients with moderate/high adherence to exercise, following medical advice (28.6 \pm 7.2 vs $23.3 \pm 5.0 \mathrm{~kg} / \mathrm{m}^{2}, P=0.002$ ). Moreover, moderate/severely depressed patients had a more severe COPD, in terms of GOLD ( $3.1 \pm 0.7$ vs $2.8 \pm 0.9, P=0.05)$ and walked shorter distances in the 6MWT $(285.0 \pm 103.0$ vs $355.0 \pm 119.0 \mathrm{~m}$, $P=0.022$ ) than patients with a low (none or mild) depression level. Lastly, patients with MCI reported more frequent depressive symptoms ( $P=0.0036)$ (Figure 1).

Among the set of variables that were considered as potential predictors of adherence to exercise prescriptions (ie, age, sex, DA, DLA, depression, anxiety, MCI and BMI), only BMI, depression and anxiety were identified by the multivariate logistic regression analysis as significant and independent predictors of adherence to exercise prescriptions. In particular, higher BMI, a higher level of depression and less anxiety were associated with lower adherence $(P=0.0004$,

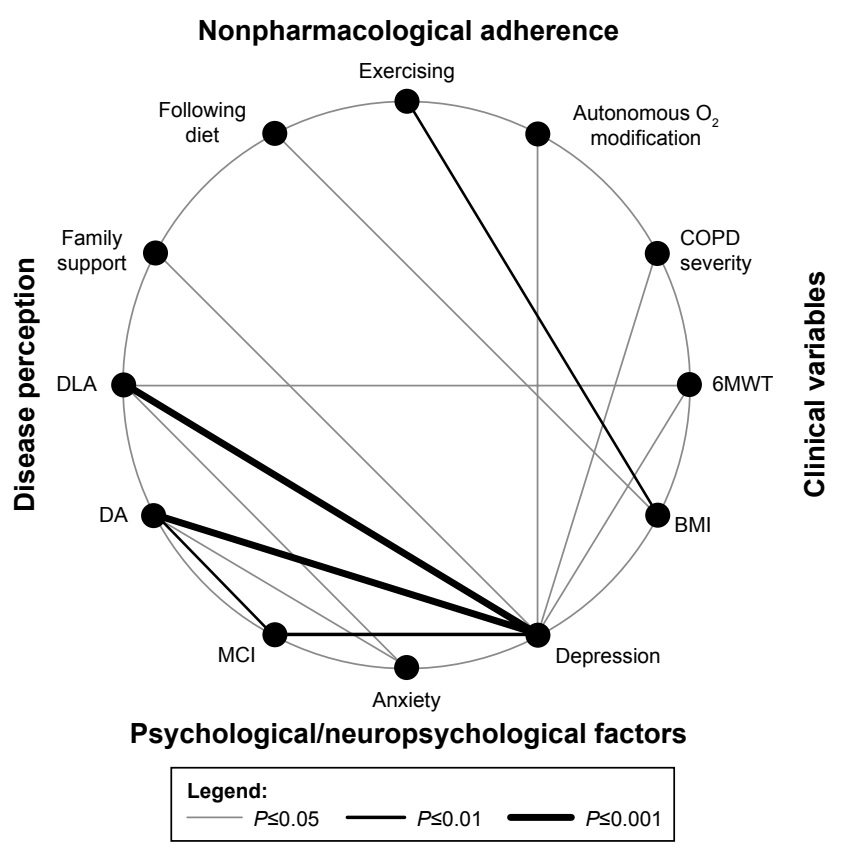

Figure I Significant relations between clinical variables, psychological/neuropsychological factors, nonpharmacological adherence and disease perception.

Abbreviations: 6MWT, 6-minute walking test; $\mathrm{BMI}$, body mass index; $\mathrm{MCl}$, mild cognitive impairment; DA, disease acceptance; DLA, disease limitations acceptance.

odds ratio $=0.796,95 \% \mathrm{CI}=0.701,0.903 ; P=0.009$, odds ratio $=0.356,95 \% \mathrm{CI}=0.165,0.770$; and $P=0.05$, odds ratio $=2.361,95 \% \mathrm{CI}=0.995,5.627$ respectively).

\section{Discussion}

With respect to previous publications, our study adds an overview on several variables related to self-reported adherence on disease management at home in COPD patients, with particular attention to psychological/neuropsychological ones, such as MCI, depression, anxiety and DA/behavioral adaptation.

From a psychological point of view, less than half of our COPD patients report depression and anxiety, from mild to severe levels. Taking into account Maurer et al's questions about the accuracy of depression and anxiety screening instruments, in our work particular attention was paid to patients' selection, validation, specificity for age and clinical condition. ${ }^{6,31}$ We took the same care with MCI evaluation using two different and well-known screening tests. Our results confirmed that MoCA is more accurate than MMSE for screening MCI, probably due to the better ability of the former to detect executive functions compared to the latter., ${ }^{9,1732}$ Regarding adherence, our data are in line with international literature concerning both assessment procedure and results. Despite the well-known limits of adherence assessment by self-report tools, which may overestimate adherence, ${ }^{20}$ between one-third 
and one half of our patients report difficulties in adhering to behavioral prescriptions, thus stressing the necessity to intervene specifically on these aspects. Regarding disease perception, one-third of our patients struggle with DA and adaptation as shown in previous studies. ${ }^{33}$ On the other hand, most of them report that they live in a supportive environment in line with the WHO ICF model, which stresses the necessity to assess the environmental factors, both as barriers and as facilitators, when dealing with a chronic disease such as COPD. ${ }^{34}$

In order to compare MCI data with the Italian normative population, MoCA raw scores were adjusted according to different levels of age and education and transformed into ES, getting a more accurate screening cutoff than with MMSE. 9,28,32 In our sample, a significantly higher percentage of MCI was highlighted when adopting MoCA-ES compared to MMSE. Given the wide range variability of cognitive impairment described in COPD literature and the different cutoffs and assessment tools adopted, ${ }^{10,11}$ our data confirm the necessity to proceed with further studies on this topic. Lastly, MoCA data transformation in ES allowed focused and effective comparisons with other variables in our study. ${ }^{9,32}$

Several features stand out when examining Figure 1. The most relevant is the opportunity to view the patient as a whole, taking into account many different aspects of being ill; clinical variables, psychological/neuropsychological factors, disease perception and nonpharmacological adherence are all interrelated. The role of depression strongly emerged due to its significant relations with many of the variables considered, from clinical aspects (COPD severity and 6MWT) to nonpharmacological adherence (autonomous LTOT modifications), from disease perception (DA, DLA and family support) to mild cognitive deficits. BMI also had a significant relation to nonpharmacological adherence (exercising and following dietary prescriptions).

From a clinical psychological point of view, other observations may be made. The relations between DA, adaptation to behavioral limitations (DLA) and psychological, neuropsychological and functional (6MWT) factors point out the importance of intervening on subjective disease perception. ${ }^{35-39}$ The higher the DA and adaptation, the lower the depression and anxiety and the better the levels of motor functionality and vice versa (Figure 1).

Since MCI was not related to the clinical variables and behavioral prescriptions, but only to psychological aspects, we could make the following considerations: MCI seemed to be a factor in its own right in the clinical variables and, on the other hand, it relates to depression, coherent with data on COPD patients with initial signs of subjective cognitive complaints. ${ }^{6,10}$
In our regression model, BMI, depression and anxiety independently predicted adherence to exercise prescriptions at home. The BMI role was expected, whereas the independent role of the psychological aspects in literature is described as indirect or mediated by other variables. ${ }^{38-42}$ Given our sample size and the specific clinical characteristics of our population, this topic deserves further studies for its relevant clinical implications.

Our study has some strengths and limitations. The strong points are that it is a multicentric study, it provides the first Italian normative MoCA data on COPD patients, and it relates clinical and psychological/neuropsychological variables to adherence at home in everyday life. The limitations are that the evaluation carried out with inpatients who voluntarily attended rehabilitation departments does not allow us to apply our findings to the general population of COPD patients; our study has a high number of variables and evaluates adherence without objective tools; and small sample size does not allow addressing generalizable conclusions.

\section{Implications for clinical practice}

Some clinical implications can be drawn from our data, which confirm what has been described in the literature regarding the factors linked to pulmonary rehabilitation. ${ }^{41-43}$ Moreover, our data may support other psychosocial potential aspects useful for understanding and consequently enhancing patients' engagement in updated COPD management. ${ }^{43}$

Independently from clinical variables, patients' adherence enhancement should focus both on psychological factors and disease perception. Up to now, few evidence-based studies have allowed the identification of adequate intervention tools to increase adherence in chronic diseases. ${ }^{7,44}$ Our data could therefore contribute to broaden the perspective on similar interventions.

Intervention on anxiety and depression should never be neglected since the following two objectives could be reached: firstly to improve the patient's emotional status and secondly to indirectly intervene on adherence self-management.

Given the multifaceted aspects of adherence and such a widespread presence of MCI in the COPD population, the rehabilitative project should be personalized and tailored to individual needs. ${ }^{45}$

Cognitive behavioral therapy or psychological interventions could be implemented ${ }^{37,46}$ in the single-case situations where the presence of psychological difficulties could interfere with disease self-management, pulmonary rehabilitation adherence and outcome. 
Finally, a self-report tool enabling heath workers to assess both pharmacological and nonpharmacological adherence, such as ASiCOLD, may allow them to focus on these aspects with indisputable advantages for a patient-centered and personalized pulmonary rehabilitative intervention for COPD patients. Further studies on this topic are much needed.

\section{Conclusion}

Stemming from our experience and from literature, we think that pulmonary rehabilitation treatment, which integrates an interdisciplinary approach, a pharmacological/nonpharmacological management and a tailored intervention, could optimize the therapeutic approach in COPD patients without neglecting their clinical, relational and psychosocial

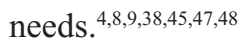

\section{Acknowledgment}

The study was funded by Clinical Scientific Institute Maugeri, IRCCS (ricerca corrente 2013).

\section{Disclosure}

The authors report no conflicts of interest in this work.

\section{References}

1. Global Initiative for Chronic Obstructive Lung Disease (GOLD) Global strategy for the diagnosis, management, and prevention of chronic obstructive pulmonary disease (updated 2017). Available from: http://goldcopd.org/gold-2017-global-strategy-diagnosis-managementprevention-copd/. Accessed June 28, 2017.

2. Spruit MA, Singh SJ, Garvey C, et al; ATS/ERS Task Force on Pulmonary Rehabilitation. An official American Thoracic Society/European Respiratory Society statement: key concepts and advances in pulmonary rehabilitation. Am J Respir Crit Care Med. 2013;188(8):e13-e64.

3. McCarthy B, Casey D, Devane D, Murphy K, Murphy E, Lacasse Y. Pulmonary rehabilitation for chronic obstructive pulmonary disease. Cochrane Database Syst Rev. 2015;23(2):CD003793.

4. Nici L. Adherence to a pulmonary rehabilitation program: start by understanding the patient. COPD. 2012;9(5):445-446.

5. Bolton CE, Bevan-Smith EF, Blakey JD, et al; British Thoracic Society Pulmonary Rehabilitation Guideline Development Group; British Thoracic Society Standards of Care Committee. British Thoracic Society guideline on pulmonary rehabilitation in adults. Thorax. 2013;68(Supp12): ii1-ii30.

6. Fan VS, Meek PM. Anxiety, depression, and cognitive impairment in patients with chronic respiratory disease. Clin Chest Med. 2014;35(2): 399-409.

7. Nieuwlaat R, Wilczynski N, Navarro T, et al. Interventions for enhancing medication adherence. Cochrane Database Syst Rev. 2014; (11):CD000011.

8. Cleutjens FAHM, Spruit MA, Ponds RWHM, et al. The impact of cognitive impairment on efficacy of pulmonary rehabilitation in patients with COPD. J Am Med Dir Assoc. 2017;18(5):420-426.

9. Selzler AM, Rodgers WM, Berry TR, Stickland MK. The importance of exercise self-efficacy for clinical outcomes in pulmonary rehabilitation. Rehabil Psychol. 2016;61(4):380-388.

10. Villeneuve S, Pepin V, Rahayel S, et al. Mild cognitive impairment in moderate to severe COPD: a preliminary study. Chest. 2012;142(6): $1516-1523$.
11. Dodd JW, Getov SV, Jones PW. Cognitive function in COPD. Eur Respir J. 2010;35(4):913-922.

12. Gudmundsson G, Gislason T, Janson C, et al. Depression, anxiety and health status after hospitalization for COPD: a multicenter study in the Nordic countries. Respir Med. 2006;100(1):87-93.

13. Eisner MD, Blanc PD, Yelin EH, et al. Influence of anxiety on health outcomes in COPD. Thorax. 2010;65(3):229-234.

14. Goodwin RD, Zvolensky MJ, Keyes KM. Nicotine dependence and mental disorders among adults in the USA: evaluating the role of mode of administration. Psychol Med. 2008;38(9):1277-1286.

15. Gudmundsson G, Gislason T, Janson C, et al. Risk factors for rehospitalisation in COPD: role of health status, anxiety and depression. Eur Respir J. 2005;26(3):414-419.

16. Xu W, Collet JP, Shapiro S, et al. Independent effect of depression and anxiety on chronic obstructive pulmonary disease exacerbations and hospitalizations. Am J Respir Crit Care Med. 2008;178(9):913-920.

17. Vestbo J, Anderson JA, Calverley PM, et al. Adherence to inhaled therapy, mortality and hospital admission in COPD. Thorax. 2009; 64(11):939-943.

18. Mäkelä MJ, Backer V, Hedegaard M, Larsson K. Adherence to inhaled therapies, health outcomes and costs in patients with asthma and COPD. Respir Med. 2013;107(10):1481-1490.

19. Wick JY. Long-term oxygen therapy: battling breathlessness. Consult Pharm. 2012;27(12):826-830.

20. Giardini A, Martin MT, Cahir C, et al. Toward appropriate criteria in medication adherence assessment in older persons: Position Paper. Aging Clin Exp Res. 2015;28(3):371-381.

21. Measso G, Cavarzeran F, Zappalà G, et al. The mini-mental state examination: normative study of an Italian random sample. Dev Neuropsychol. 1993;9(2):77-85.

22. Costantini M, Musso M, Viterbori P, et al. Detecting psychological distress in cancer patients: validity of the Italian version of the Hospital Anxiety and Depression Scale. Support Care Cancer. 1999;7(3): 121-127.

23. Yesavage JA, Brink TL, Rose TL, et al. Development and validation of a geriatric depression screening scale: a preliminary report. JPsychiatr Res. 1982;17(1):37-49.

24. Ghisi M, Flebus GB, Montano A, Sanavio E, Sica C. BDI-II. Beck Depression Inventory - II. Firenze: Giunti O.S.; 2006.

25. Morisky DE, Green LW, Levine DM. Concurrent and predictive validity of a self-reported measure of medication adherence. Med Care. 1986;24(1):67-74.

26. Majani G, Pierobon A, Giardini A, Callegari S. Valutare e favorire l'aderenza alle prescrizioni in riabilitazione cardiologica e pneumologica. [Screening and promoting the adherence in cardiological and pulmonary rehabilitation]. In: I Manuali della Fondazione Maugeri. Pavia: PI-ME; 2007. Italian.

27. Nasreddine ZS, Phillips NA, Bédirian V, et al. The Montreal Cognitive Assessment, MoCA: a brief screening tool for mild cognitive impairment. J Am Geriatr Soc. 2005;53(4):695-699.

28. Conti S, Bonazzi S, Laiacona M, Masina M, Coralli MV. Montreal Cognitive Assessment (MoCA)-Italian version: regression based norms end equivalent scores. Neurol Sci. 2015;36(2):209-214.

29. Julian LJ. Measures of anxiety: State-Trait Anxiety Inventory (STAI), Beck Anxiety Inventory (BAI), and Hospital Anxiety and Depression Scale-Anxiety (HADS-A). Arthritis Care Res (Hoboken). 2011;63(Suppl 11):S467-S472.

30. Smarr KL, Keefer AL. Measures of depression and depressive symptoms: Beck Depression Inventory-II (BDI-II), Center for Epidemiologic Studies Depression Scale (CES-D), Geriatric Depression Scale (GDS), Hospital Anxiety and Depression Scale (HADS), and Patient Health Questionnaire-9 (PHQ-9). Arthritis Care Res (Hoboken). 2011;63(Suppl 11): S454-S466.

31. Maurer J, Rebbapragada V, Borson S, et al; ACCP Workshop Panel on Anxiety and Depression in COPD. Anxiety and depression in COPD: current understanding, unanswered questions, and research needs. Chest. 2008;134(4 Suppl):43S-56S. 
32. Dulohery MM, Schroeder DR, Benzo RP. Cognitive function and living situation in COPD: is there a relationship with self-management and quality of life? Int J Chron Obstruct Pulmon Dis. 2015;10:1883-1889.

33. Uchmanowicz I, Jankowska-Polanska B, Motowidlo U, Uchmanowicz B, Chabowski M. Assessment of illness acceptance by patients with COPD and the prevalence of depression and anxiety in COPD. Int J Chron Obstruct Pulmon Dis. 2016;11:963-970.

34. Stucki A, Stoll T, Cieza A, et al. ICF Core Sets for obstructive pulmonary diseases. J Rehabil Med. 2004;(Suppl 44):114-120.

35. Pierobon A, Giardini A, Callegari S, Majani G. Psychological adjustment to a chronic illness: the contribution from cognitive behavioural treatment in a rehabilitation setting. G Ital Med Lav Ergon. 2011;33(Suppl 1A): A11-A18.

36. de Sousa Pinto JM, Martín-Nogueras AM, Morano MT, Macêdo TE, Arenillas JI, Troosters T. Chronic obstructive pulmonary disease patients' experience with pulmonary rehabilitation: a systematic review of qualitative research. Chron Respir Dis. 2013;10(3):141-157.

37. Almagro P, Castro A. Helping COPD patients change health behavior in order to improve their quality of life. Int J Chron Obstruct Pulmon Dis. 2013;8:335-345.

38. Schüz N, Walters JA, Cameron-Tucker H, Scott J, Wood-Baker R, Walters EH. Patient anxiety and depression moderate the effects of increased self-management knowledge on physical activity: a secondary analysis of a randomised controlled trial on health-mentoring in COPD. COPD. 2015;12(5):502-509.

39. Pierobon A, Giardini A, Majani G, et al. Into the cognitive constructs related to adherence to treatment in CHD outpatients: the importance of accepting the disease limitations. Monaldi Arch Chest Dis. 2009;72:130-138.

40. Park SK, Richardson CR, Holleman RG, Larson JL. Physical activity in people with COPD, using the National Health and Nutrition Evaluation Survey dataset. Heart Lung. 2013;42(4):235-240.
41. Hartman JE, Boezen HM, de Greef MH, Ten Hacken NH. Physical and psychological factors associated with physical activity in patients with chronic obstructive pulmonary disease. Arch Phys Med Rehabil. 2013;94(12):2396-2402.

42. Altenburg WA, Bossenbroek L, de Greef MH, Kerstjens HA, ten Hacken NH, Wempe JB. Functional and psychological variables both affect daily physical activity in COPD: a structural equations model. Respir Med. 2013;107(11):1740-1747.

43. Müllerová H, Landis SH, Aisanov Z, et al. Health behaviors and their correlates among participants in the Continuing to Confront COPD International Patient Survey. Int J Chron Obstruct Pulmon Dis. 2016;11:881-890.

44. Costa E, Giardini A, Savin M, et al. Interventional tools to improve medication adherence: review of literature. Patient Prefer Adherence. 2015;9:1303-1314.

45. Ambrosino N, Clini EM. Response to pulmonary rehabilitation: toward personalised programmes? Eur Respir J. 2015;46(6):1538-1540.

46. Harrison SL, Goldstein R, Desveaux L, Tulloch V, Brooks D. Optimizing nonpharmacological management following an acute exacerbation of chronic obstructive pulmonary disease. Int J Chron Obstruct Pulmon Dis. 2014;9:1197-1205.

47. Bratås O, Espnes GA, Rannestad T, Walstad R. Characteristics of patients with chronic obstructive pulmonary disease choosing rehabilitation. J Rehabil Med. 2010;42(4):362-367.

48. Baldi S, Pinna GD, Bruschi C, et al. Medicinal clays improve the endurance of loaded inspiratory muscles in COPD: a randomized clinical trial of nonpharmacological treatment. Int J Chron Obstruct Pulmon Dis. 2015;10:2235-2248. 


\section{Supplementary material}

\section{Appendix A Adherence Schedule in Chronic Obstructive Lung Disease-Revised}

Surname Name.

Date.

These questions are about some of your ideas regarding your illness and treatment. There are no right or wrong answers. When responding, refer only to what you think about your illness and how you take care of yourself. Please put a cross by the answer you want to give.

\begin{tabular}{|c|c|c|c|c|}
\hline Questions & Answers & & & \\
\hline I. Do you accept your disease? & Not at all & A little Enough & Much & Very much \\
\hline 2. Do you accept the limitation related to your disease? & Not at all & A little Enough & Much & Very much \\
\hline 3. Does your family help you manage your disease? & Not at all & A little Enough & Much & Very much \\
\hline 4. Do your friends and/or other people you know help you manage your disease? & Not at all & A little Enough & Much & Very much \\
\hline 5. Do you ever forget to take your medicines? & Not at all & A little Enough & Much & Very much \\
\hline 6. Do you ever change the time you take your medicines? & Not at all & A little Enough & Much & Very much \\
\hline 7. Do you ever change your treatment according to how you feel? & Not at all & A little Enough & Much & Very much \\
\hline 8. Do you ever change oxygen therapy prescriptions (amount and timing)? (If pertinent) & Not at all & A little Enough & Much & Very much \\
\hline 9. When you are at home, do you manage to follow the diet suggested to you? & Not at all & A little Enough & Much & Very much \\
\hline 10. When you are at home, do you manage to avoid smoking? (If pertinent) & Not at all & A little Enough & Much & Very much \\
\hline II. When you are at home, do you manage to exercise at least three times a week? & Not at all & A little Enough & Much & Very much \\
\hline
\end{tabular}

Note: Data from Majani et al.'

\section{Reference}

1. Majani G, Pierobon A, Giardini A, Callegari S. Valutare e favorire l'aderenza alle prescrizioni in riabilitazione cardiologica e pneumologica. [Screening and promoting the adherence in cardiological and pulmonary rehabilitation]. In: I Manuali della Fondazione Maugeri. Pavia: PI-ME; 2007.

\section{Publish your work in this journal}

The International Journal of COPD is an international, peer-reviewed journal of therapeutics and pharmacology focusing on concise rapid reporting of clinical studies and reviews in COPD. Special focus is given to the pathophysiological processes underlying the disease, intervention programs, patient focused education, and self management protocols.

\section{Dovepress}

This journal is indexed on PubMed Central, MedLine and CAS. The manuscript management system is completely online and includes a very quick and fair peer-review system, which is all easy to use. Visit $\mathrm{http}: / / \mathrm{www}$. dovepress.com/testimonials.php to read real quotes from published authors. 